\title{
Potential suppressive effects of gentian violet on human breast cancer MDA-MB-231 cells in vitro: Comparison with gemcitabine
}

\author{
MASAYOSHI YAMAGUCHI $^{1}$ and TOMIYASU MURATA ${ }^{2}$
}

\author{
${ }^{1}$ Department of Hematology and Medical Oncology, Winship Cancer Institute, Emory University School of Medicine, \\ Atlanta, GA 30322, USA; ${ }^{2}$ Laboratory of Analytical Neurobiology, Faculty of Pharmacy, \\ Meijo University, Nagoya, Aichi 468-8503, Japan
}

Received October 22, 2015; Accepted June 7, 2016

DOI: $10.3892 / 01.2016 .4773$

\begin{abstract}
Gentian violet (GV), a cationic triphenylmethane dye, is used as an antifungal and antibacterial agent. Recently, attention has been focused on GV as a potential chemotherapeutic and antiangiogenic agent. The present study was undertaken to determine the suppressive effects of GV on human breast cancer MDA-MB-231 cells in vitro. The proliferation of MDA-MB-231 cells was suppressed by culture with GV (1-200 nM). The suppressive effects of GV on cell proliferation were not potentiated in the presence of various inhibitors that induce cell cycle arrest in vitro. This finding suggested that GV inhibits $\mathrm{G} 1$ and $\mathrm{G} 2 / \mathrm{M}$ phase cell cycle arrest in MDA-MB-231 cells. The suppressive effects of $\mathrm{GV}$ on proliferation are mediated through the inhibition of various signaling pathways or nuclear transcription in vitro. Moreover, the suppressive effects of GV on cell proliferation were compared with that of gemcitabine, a strong antitumor agent that induces nuclear DNA damage. Notably, the culture with gemcitabine $>50 \mathrm{nM}$ suppressed cell proliferation, while the effects of $\mathrm{GV}$ were observed at $>1 \mathrm{nM}$. The suppressive effects of gemcitabine on cell proliferation were not potentiated by GV. Overall, the present study demonstrated that GV exhibits a potential suppressive effect on the proliferation of human breast cancer MDA-MB-231 cells in vitro.
\end{abstract}

\section{Introduction}

Various types of cancer induce bone metastasis, which leads to serious bone loss and fractures. Bone metastasis occurs in $70-80 \%$ of patients with advanced stage breast cancer (1-4), and induces severe pathological bone fractures, pain, hypercalcemia, and spinal cord and nerve-compression

Correspondence to: Dr Masayoshi Yamaguchi, Department of Hematology and Medical Oncology, Winship Cancer Institute, Emory University School of Medicine, 1365C Clifton Road NE, Atlanta, GA 30322, USA

E-mail: yamamasa1155@yahoo.co.jp

Key words: gentian violet, human breast cancer, MDA-MB-231 cells, cell proliferation, cell cycle, cell death syndromes $(3,5)$. This bone disorder is frequently causes morbidity and mortality. Tumor invasion of the bone tissues is associated with the recruitment of osteoclasts and osteoblasts, resulting in growth factor liberation from the bone matrix. Furthermore, these growth factors can enhance tumor growth, resulting in a cycle of bone metastasis $(4,5)$.

Breast cancer cells promote osteoclast formation via the secretion of osteoporotic cytokines, including parathyroid hormone-related peptide, tumor necrosis factor- $\alpha$ (TNF- $\alpha$ ), prostaglandin $\mathrm{E}_{2}$, leukemia inhibitory factor, and interleukin-1, $-6,-8,-11,-15$ and $-17(4,6)$. Constitutively-activated nuclear factor- $\kappa \mathrm{B}(\mathrm{NF}-\kappa \mathrm{B})$ in breast cancer cells has been shown to play a crucial role in osteolysis, which stimulates osteoclastogenesis. Moreover, breast cancer cells stimulate the production of granulocyte macrophage colony-stimulating factor, which enhances development from monocytes to osteoclasts (7). In addition, progesterone receptor-positive mammary epithelial cancer cells express receptor activator of $N F-\kappa B$ ligand (RANKL), which mediates the proliferation of epithelial cells and carcinogenesis (8). In addition, breast cancer cells suppress the function of osteoblasts. This is demonstrated by an increase in apoptosis and a decrease in proteins required for new bone formation (6). Bone loss induced by breast cancer bone metastasis is based on activated osteoclastic bone resorption and suppressed osteoblastic bone formation.

Bisphosphonate or anti-RANKL antibody (denosumab) is used as the current standard care for patients with bone metastasis (9). Bisphosphonate inhibits osteoclastic bone resorption, but does not possess osteogenic effects. Denosumab suppresses osteoclast maturation by inhibiting the binding of RANKL to RANK, which is the receptor of RANKL in preosteoclasts and mature osteoclasts. These drugs target bone resorption mediated through osteoclasts. However, agents that stimulate osteogenic bone formation to repair bone destruction have been poorly developed.

Gentian violet (GV), a triaminophenylmethane dye, has been used extensively in medicine for a century, and it has a potent anti-microbial action (10). Furthermore, recent studies have suggested the angiogenic and anticancer properties of GV, and this chemical is currently experiencing renewed interest in medical applications $(11,12)$. Our recent study demonstrated that $\mathrm{GV}$ inhibits nuclear factor- $\kappa \mathrm{B}(\mathrm{NF}-\kappa \mathrm{B})$ activity, and that this agent can potently enhance osteoblast differentiation 
and mineralization, but suppress the differentiation to osteoclasts (13). Thus, GV may regulate the differentiation of bone cells in vitro. Further development of GV as an anti-osteoporotic and/or anti-inflammatory agent may be expected.

Moreover, GV may possess preventive effects on bone loss induced by cancer cell bone metastasis. However, the anticancer effects of GV on human breast cancer bone metastatic cells have been poorly investigated. The present study was undertaken to determine whether GV exhibits a suppressive effect on the proliferation of human breast cancer MDA-MB-231 cells in vitro. The results showed that GV potently suppresses the proliferation of human breast cancer MDA-MB-231 cells.

\section{Materials and methods}

Materials. Dulbecco's modified Eagle's medium (DMEM) with $4.5 \mathrm{~g} / 1$ glucose, L-glutamine and sodium pyruvate, and antibiotics [penicillin and streptomycin $(\mathrm{P} / \mathrm{S})$; $5,000 \mathrm{U} / \mathrm{ml}$ and $5,000 \mu \mathrm{g} / \mathrm{ml}$, respectively] were purchased from Gibco Laboratories (Grand Island, NY, USA). Fetal bovine serum (FBS) was obtained from HyClone (Logan, UT, USA). Gentian violet, sodium butyrate, roscovitine, sulforaphane, PD98059, staurosporine, wortmannin, 5,6-dichloro-1- $\beta$-D-ribofuranosylbenzimidazole (DRB) and all other reagents were purchased from Sigma-Aldrich (St. Louis, MO, USA) unless otherwise specified. Gemcitabine was obtained from Hospira, Inc. (Lake Forest, IL, USA). Gemcitabine was diluted in phosphate-buffered saline (PBS) and other reagents were dissolved in $100 \%$ ethanol to use in the experiments.

Cancer cells. MDA-MB-231 human breast cancer cells lack the receptors for progesterone, estrogen and human epithelial growth factor receptor 2 , and are therefore considered as triple negative (14). However, MDA-MB-231 cells do express epithelial growth factor receptor (EGFR) at high levels, and activation of this receptor and its downstream signaling events enhance the migration, proliferation, invasion and progression of the malignant phenotype of breast cancer cells (14). The present study used estrogen-independent bone-seeking triple negative human breast cancer MDA-MB-231 cells $\left(1 \times 10^{6}\right.$ cells/ $\mathrm{ml}$ of DMEM containing $10 \% \mathrm{FBS}$ and $0.1 \% \mathrm{P} / \mathrm{S}$ ), which were stored at $-80^{\circ} \mathrm{C}$. The cells were obtained from the American Type Culture Collection (Rockville, MD, USA).

Proliferation in cancer cells. The breast cancer MDA-MB-231 cells $\left(1 \times 10^{5} / \mathrm{ml}\right.$ per well) were cultured in a 24-well plate using DMEM containing 10\% FBS and 1\% P/S in the presence or absence of $\mathrm{GV}(1,10,50,100$ or $200 \mathrm{nM})$ for $1,3,7$ or 14 days in a water-saturated atmosphere containing $5 \% \mathrm{CO}_{2}$ and $95 \%$ air at $37^{\circ} \mathrm{C}(15-17)$. In separate experiments, the MDA-MB-231 cells $\left(1 \times 10^{5} / \mathrm{ml}\right.$ per well) were cultured in DMEM containing $10 \%$ FBS and $1 \% \mathrm{P} / \mathrm{S}$ in the presence of either ethanol $(0.1 \%$ final concentration; control), sodium butyrate (10 and $100 \mu \mathrm{M})$, roscovitine (10 and $100 \mathrm{nM})$, sulforaphane (1 and $10 \mathrm{nM})$, PD98059 $(1 \mu \mathrm{M})$, staurosporin $(0.1 \mu \mathrm{M})$, wortmannin $(1 \mu \mathrm{M})$, DRB $(1 \mu \mathrm{M})$ or gemcitabine (100 $\mathrm{nM})$ for 3-7 days. Subsequent to the culture process, the cells were detached from each culture dish and counted $(16,17)$. In addition, to determine the effects of GV on MDA-MB-231 cells that reached confluence,
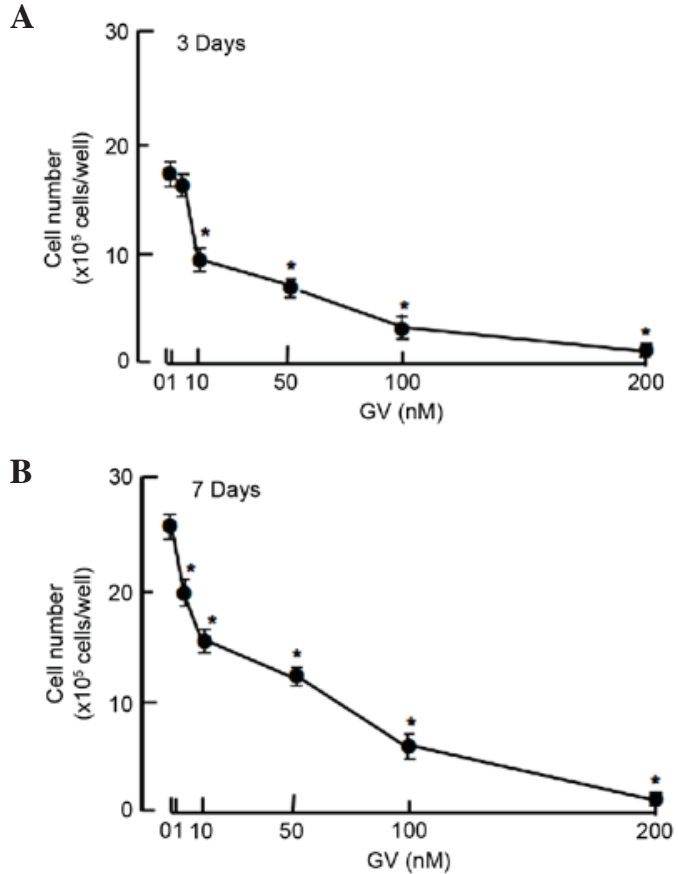

Figure 1. Gentian violet (GV) potently suppresses MDA-MB-231 human breast cancer cell proliferation in vitro. Cells were cultured in Dulbecco's modified Eagle's medium in the presence or absence of GV (1-200 nM) for (A) 3 or (B) 7 days. After culture, the number of attached cells on each dish was counted. Data are presented as the mean \pm standard deviation of 2 replicate wells per dataset using different dishes and cell preparations. ${ }^{*} \mathrm{P}<0.001$ vs. control (one-way analysis of variance, Tukey-Kramer post-hoc test).

the cells $\left(1 \times 10^{5}\right.$ cells $/ \mathrm{ml}$ per well $)$ were cultured using a 24-well plate in DMEM containing 10\% FBS and 1\% P/S in the absence of GV for 7 days until they reached confluence, and then the cells were cultured in the presence of GV $(1,10$, 50,100 or $200 \mathrm{nM}$ ) for 3 days (18). Following this, the cells were detached from each culture dish and counted.

Cell counting. Following trypsinization of each culture dish using $0.2 \%$ trypsin plus $0.02 \%$ EDTA in $\mathrm{Ca}^{2+} / \mathrm{Mg}^{2+}$-free PBS for $2 \mathrm{~min}$ at $37^{\circ} \mathrm{C}$, detached cells from the dishes were collected after centrifugation at $150 \mathrm{x}$ g for $5 \mathrm{~min}(16-18)$. The cells were resuspended in PBS solution and stained with eosin. Cell numbers were counted under a microscope (Olympus MTV-3; Olympus, Tokyo, Japan) using a hemocytometer plate. For each dish, the average of two counts was used. Cell number is shown as the number per well of each plate.

Statistical analysis. Statistical significance was determined using GraphPad InStat version 3 for Windows XP (GraphPad Software Inc., La Jolla, CA, USA). Multiple comparisons were performed by one-way analysis of variance with Tukey-Kramer multiple comparisons post-hoc test for parametric data as indicated. $\mathrm{P}<0.05$ was considered to indicate a statistically significant difference.

\section{Results}

To determine the effects of GV on the proliferation of human breast cancer MDA-MB-231 cells in vitro, the cancer cells were 

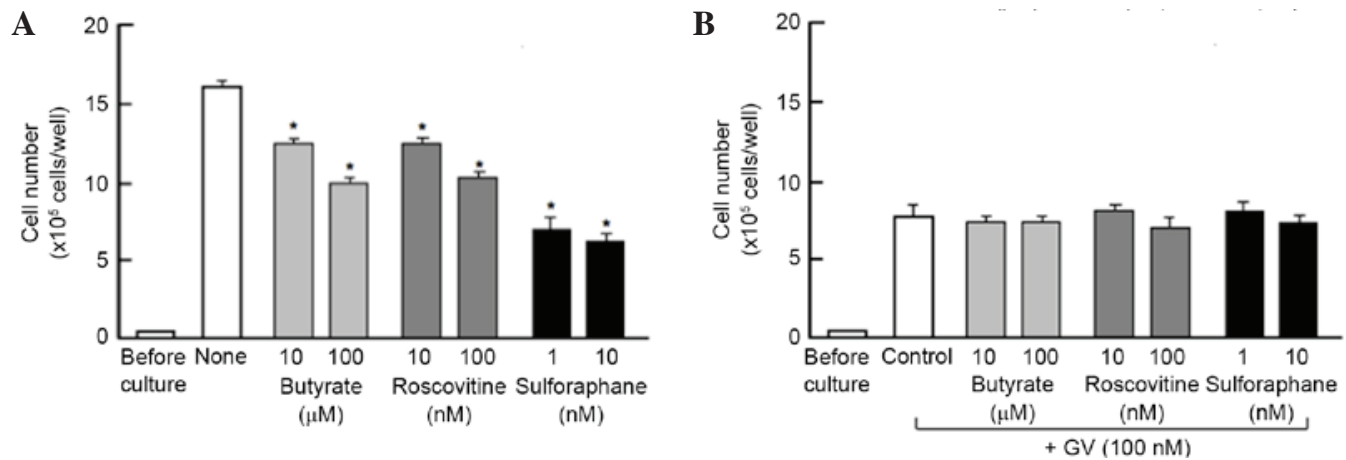

Figure 2. Gentian violet (GV) induces cell cycle arrest in human breast cancer MDA-MB-231 cells in vitro. Cells were cultured for 3 days in the (A) absence or (B) presence of $\mathrm{GV}(100 \mathrm{nM})$ with or without butyrate $(10$ and $100 \mu \mathrm{M})$, roscovitine $(10$ and $100 \mathrm{nM})$ or sulforaphane $(1$ and $10 \mathrm{nM})$. After culture, the number of attached cells on each dish was counted. Data are presented as the mean \pm standard deviation of 2 replicate wells per dataset using different dishes and cell preparations. ${ }^{*} \mathrm{P}<0.001$ vs. control (white bar) (one-way analysis of variance, Tukey-Kramer post-hoc test).
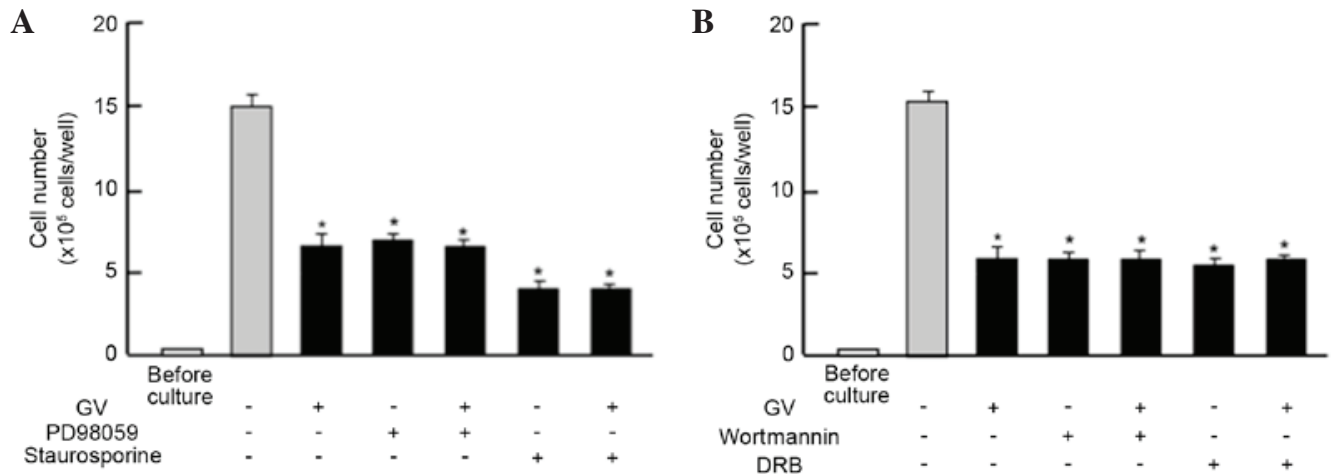

Figure 3. Suppressive effects of gentian violet (GV) on cell proliferation are not altered in the presence of inhibitors associated with intracellular signaling and transcriptional activity in MDA-MB-231 human breast cancer cells in vitro. (A) Cells were culture for 3 days in the presence of GV (100 nM) with or without PD98059 $(1 \mu \mathrm{M})$ or staurosporin $(0.1 \mu \mathrm{M})$. (B) Cells were cultured for 3 days in the presence of $\mathrm{GV}(100 \mathrm{nM})$ with or without wortmannin $(1 \mu \mathrm{M})$ or DRB $(1 \mu \mathrm{M})$. After culture, the number of attached cells on each dish was counted. Data are presented as the mean \pm standrad deviation of 2 replicate wells per dataset using different dishes and cell preparations. "P<0.001 vs. control (grey bar). DRB, 5,6-dichloro-1- $\beta$-D-ribofuranosylbenzimidazole.
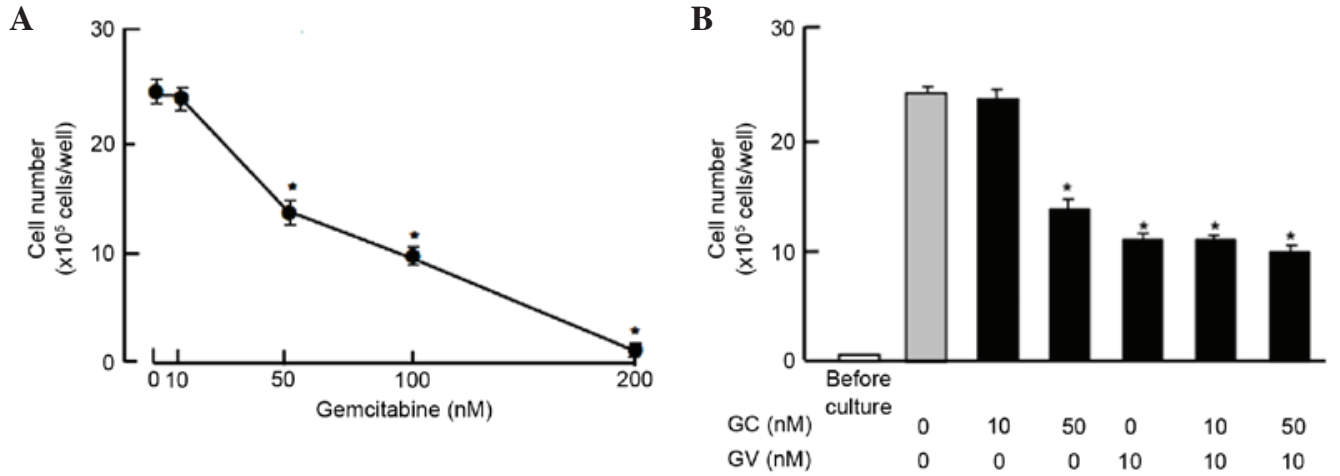

Figure 4. Suppressive effects of gentian violet (GV) on human breast cancer MDA-MB-231 cells show potential as compared with gemcitabine (GC) in vitro. (A) Cells were cultured for 7 days in the presence of gemcitabine (10,50,100 or $200 \mathrm{nM}$ ). (B) Cells were cultured for 7 days in the presence of GV (10 nM) with or without gemcitabine $(10$ or $50 \mathrm{nM})$. After culture, the number of attached cells on each dish was counted. Data are presented as the mean \pm standard deviation of 2 replicate wells per dataset using different dishes and cell preparations. ${ }^{*} \mathrm{P}<0.001$ vs. control (grey bar) (one-way analysis of variance, Tukey-Kramer post-hoc test).

cultured in the presence of GV for 3 or 7 days. Cell numbers were increased with increasing culture periods. This increase was suppressed after culture with GV (1-200 nM) for 3 (Fig. 1A) and 7 (Fig. 1B) days. Thus, GV was found to exhibit suppressive effects on the proliferation of the MDA-MB-231 cells in vitro. In addition, the MDA-MB-231 cells that reached confluence after culture for 7 days were cultured for an additional 3 days in the presence of GV (1-200 nM). Cell number was significantly $(\mathrm{P}=0.001)$ decreased after culture with GV (10-200 nM) (data not shown), suggesting that GV partly stimulates cell death.

To determine a mechanistic characterization, the present study determined whether the suppressive effects of GV on the proliferation of MDA-MB-231 cells are altered using various inhibitors that induce cell cycle arrest in vitro 
(Fig. 2). Cells were cultured for 3 days with or without butyrate $(10$ and $100 \mu \mathrm{M})$, roscovitine $(10$ and $100 \mathrm{nM})$ or sulforaphane (1 and $10 \mathrm{nM})(17,19,20)$. The proliferation of the MDA-MB-231 cells, which were cultured in the absence of $\mathrm{GV}$, was suppressed in the presence of these inhibitors (Fig. 2A). The suppressive effects of these inhibitors on cell proliferation was not altered in the presence of GV $(100 \mathrm{nM})$ (Fig. 2B). This finding suggested that GV induces $\mathrm{G} 1$ and $\mathrm{G} 2 / \mathrm{M}$ phase cell cycle arrest in MDA-MB-231 cells.

Next, the study determined whether the suppressive effects of $\mathrm{GV}$ on the proliferation in MDA-MB-231 cells are changed by various signaling factors that suppress proliferation. The suppressive effects of $\mathrm{GV}(100 \mathrm{nM})$ on the proliferation of the MDA-MB-231 cells were not altered in the presence of PD98059 $(1 \mu \mathrm{M})$, an extracellular signal-regulated kinase (ERK) inhibitor (21), or staurosporin $(0.1 \mu \mathrm{M})$, an inhibitor of protein kinase $\mathrm{C}$ (22) (Fig. 3A). In addition, the suppressive effects of $\mathrm{GV}$ on cell proliferation were not enhanced in the presence of wortmannin $(1 \mu \mathrm{M})$, an inhibitor of phosphatidylinositol 3-kinase (PI3K) (23), or DRB (1 $\mu \mathrm{M})$, an inhibitor of transcriptional activity with RNA polymerase II inhibition (24) (Fig. 3B).

Moreover, the suppressive effects of GV on the proliferation of the MDA-MB-231 cells were compared with those of gemcitabine, a strong antitumor agent that induces nuclear DNA damage (25). Culture with gemcitabine (50, 100 and $300 \mathrm{nM}$ ) for 7 days suppressed cell proliferation, while such effects were not observed at a concentration of $10 \mathrm{nM}$ gemcitabine (Fig. 4A). The suppressive effects of gemcitabine (10 and $50 \mathrm{nM}$ ) on proliferation were not potentiated in the presence of $\mathrm{GV}(10 \mathrm{nM})$, which exhibited suppressive effects on the proliferation of the MDA-MB-231 cells (Fig. 4B).

\section{Discussion}

The present study demonstrated that GV exhibits a potent suppressive effect on the proliferation of human breast cancer MDA-MB-231 cells in vitro. The suppressive effects of GV on cell proliferation were characterized using various factors that inhibit cell cycle-related signaling processes. The suppressive effects of GV on the proliferation of the MDA-MB-231 cells were not changed by the presence of butyrate, roscovitine or sulforaphan, which induce cell cycle arrest. Roscovitine is a potent and selective inhibitor of the cyclin-dependent kinases cdc2, cdk2m and cdk5 (19), sulforaphane induces G2/M phase cell cycle arrest (20) and butyrate induces the inhibition of G1 progression (17). In the present study, GV was suggested to induce $\mathrm{G} 1$ and $\mathrm{G} 2 / \mathrm{M}$ phase cell cycle arrest in the MDA-MB-231 cells.

The suppressive effects of $\mathrm{GV}$ on the proliferation of the MDA-MB-231 cells were not altered in the presence of various inhibitors that regulate intracellular signaling pathways in vitro. The suppressive effects of $\mathrm{GV}$ on cell proliferation were not potentiated in the presence of PD98059, an inhibitor of the ERK/mitogen-activated protein kinase (MAPK) signaling pathway (21), staurosporin, an inhibitor of the calcium-dependent protein kinase C signaling pathway (22), or wortmannin, an inhibitor of the PI3K/Akt signaling pathway (23). GV appeared to suppress cell proliferation, which is mediated through the inhibition of various signaling pathways associated with ERK/MAPK, calcium and PI3/Akt in breast cancer MDA-MB-231 cells.

Moreover, the suppressive effects of GV on cell proliferation were not altered in the presence of DRB, an inhibitor of transcriptional activity with RNA polymerase II inhibition (24). GV may also suppress transcriptional activity in the nuclei of MDA-MB-231 cells. Gemcitabine is an antitumor agent that induces nuclear DNA damage (25). This agent suppresses cell proliferation and stimulates apoptotic cell death in various types of cancer cells. In the present study, the effects of GV on proliferation and cell death were not enhanced in the presence of gemcitabine in the MDA-MB-231 cells, suggesting that GV partly acts in a process involved in the action of gemcitabine. Notably, GV exhibited suppressive effects on cell proliferation at lower concentrations compared with gemcitabine, indicating that GV exhibits a potential effect in breast cancer cells. GV may provide a useful tool as a novel antitumor agent.

$\mathrm{GV}$ has been shown to potently prevent TNF- $\alpha$-induced suppression of osteoblastic mineralization and RANKL-induced stimulation of osteoclastogenesis by antagonizing the activation of $\mathrm{NF}-\kappa \mathrm{B}$ signaling in preosteoblastic cells and RAW267.4 preosteoclastic cells in vitro (13). Moreover, GV has been demonstrated to potently prevent suppressed osteoblastic mineralization and enhanced osteoclastogenesis induced by MDA-MB-231 cells in bone marrow culture in vitro (26). From these findings, it has been suggested that GV exhibits a potent suppressive effect on the activation of NF- $\kappa \mathrm{B}$ signaling in MDA-MB-231 cells.

In conclusion, the present study demonstrated that GV potently suppresses the proliferation of human breast cancer MDA-MB-231 cells in vitro, and that this effect of GV has potential compared with that of gemcitabine, which is clinically used as an anticancer drug (25). GV may be a novel useful tool in the prevention and therapy of breast cancer in vivo.

\section{References}

1. Boyce BF, Yoneda T and Guise TA: Factors regulating the growth of metastasis cancer in bone. Endocr Relat Cancer 6: 333-347, 1999.

2. Mundy GR: Metastasis to bone: Causes, consequences and therapeutic opportunities. Nat Rev Cancer 2: 584-593, 2002.

3. Roodman CD: Mechanism of bone metastasis. N Engl J Med 350: 1655-1664, 2004.

4. Akhtari M, Mansuri J, Newman KA, Guise TM and Seth P: Biology of brest cancer bone metastasis. Cancer Biol Ther 7: 3-9, 2008.

5. Coleman RE: Metastatic bone disease: Clinical features, pathophysiology and treatment strategies. Cancer Treat Rev 27: 165-176, 2001.

6. Chen YC, Sosnoski DM and Mastro AM: Breast cancer metastasis to the bone: Mechanisms of bone loss. Breast Cancer Res 12: 215, 2010.

7. Park BK, Zhang H, Zeng Q, Dai J, Keller ET, Giordano T, Gu K, Shah V, Pei L, Zarbo RJ, et al: NF-kappaB in breast cancer cells promotes osteolytic bone metastasis by inducing osteoclastogenesis via GM-CSF. Nat Med 13: 62-69, 2007.

8. Gonzalez-Suarez E, Jacob AP, Jones J, Miller R, Roudier-Meyer MP, Enwert R, Pinkas J, Branstetter D and Dougall WC: RANK ligand mediates progestin-induced mammary epithelial proliferation and carcinogenesis. Nature 468: 103-107, 2010.

9. Weilbaecher KN, Guise TA and McCauley LK: Cancer to bone: A fatal attraction. Nat Rev Cancer 11: 411-425, 2011.

10. Berrios RL and Arbiser JL: Effectiveness of gentian violet and similar products commonly used to treat pyodermas. Dermatol Clin 29: 69-73, 2011 
11. Perry BN, Govindarajan B, Bhandarkar SS, Knaus UG, Valo M Sturk C, Carrillo CO, Sohn A, Cerimele F, Dumont D, et al: Pharmacologic blockade of angiopoietin-2 is efficacious against model hemangiomas in mice. J Invest Dermatol 126: 2316-2322, 2006.

12. Zhang X, Zheng Y, Fried LE, Du Y, Montano SJ, Sohn A, Lefkove B, Holmgren L, Arbiser JL, Holmgren A and Lu J: Disruption of the mitochondrial thioredoxin system as a cell death mechanism of cationic triphenylmethanes. Free Radic Biol Med 50: 811-820, 2011.

13. Yamaguchi M, Vikulina1 T, Arbiser JL and Weitzmann MN Suppression of $\mathrm{NF}-\kappa \mathrm{B}$ activation by gentian violet promotes osteoblastogenesis and suppresses osteoclastogenesis. Curr Mol Med 14: 783-792, 2014.

14. Yoneda T, Williams PJ, Hiraga T, Niewolna $M$ and Nishimura $R$ A bone-seeking clone exhibits different biological properties from the MDA-MB-231 parental human breast cancer cells and a brain-seeking clone in vivo and in vitro. J Bone Miner Res 16 1486-1495, 2001

15. Yamaguchi M, Zhu S, Weitzmann MN, Snyder JP and Shoji M: Curcumin analog UBS109 prevents bone marrow osteoblastogenesis and osteoclastogenesis disordered by coculture with breast cancer MDA-MB-231 bone metastatic cells in vitro. Mol Cell Biochem 401: 1-10, 2015.

16. Misawa H, Inagaki S and Yamaguchi M: Suppression of cell proliferation and deoxyribonucleic acid synthesis in cloned rat hepatoma H4-II-E cells overexpressing regucalcin. J Cell Biochem 84: 143-149, 2001.

17. Yamaguchi $\mathrm{M}$ and Daimon $\mathrm{Y}$ : Overexpression of regucalcin suppresses cell proliferation in cloned rat hepatoma H4-II-E cells: Involvement of intracellular signaling factors and cell cycle-related genes. J Cell Biochem 95: 1169-1177, 2005.

18. Izumi $\mathrm{T}$ and Yamaguchi $\mathrm{M}$ : Overexpression of regucalcin suppresses cell death in cloned rat hepatoma H4-II-E cells induced by tumor necrosis factor-alpha or thapsigargin. J Cell Biochem 92: 296-306, 2004.
19. Meijer L, Borgne A, Mulner O, Chong JP, Blow JJ, Inagaki N, Inagaki M, Deleros JG and Moulinoux JP: Biochemical and cellular effects of roscovitine, a potent and selective inhibitor of the cyclin-dependent kinases cdc2, cdk2 and cdk5. Eur J Biochem 243: 527-536, 1997.

20. Singh SV, Herman-Antosiewice A, Singh AV, Lew KL, Strivastava SK, Kamath R, Brown KD, Zhang L and Baskaran R: Sulforaphan-induced G2/M phase cell cycle arrest involves checkpoint kinase 2-mediated phosphorylation of cell division cycle 25C. J Biol Chem 279: 25813-25822, 2004.

21. Chen S, Wang Y, Ruan W, Wang X and Pan C: Reversing multidrug resistance in hepatocellular carcinoma cells by inhibiting extracellular signal-regulated kinase/mitogen-activated protein kinase signaling pathway activity. Oncol Lett 8: 2333-2339, 2014.

22. Chen QW, Edvinsson L and Xu CB: Role of ERK/MAPK in endothelin receptor signaling in human aortic smoth muscle cells. BMC Cell Biol 10: 52, 2009.

23. Serrano-Nascimento C, da Silva Teixeira S, Nicola JP, Nachbar RT, Masini-Repiso AM and Nunes MT: The acute inhibitory effect of iodide excess on sodium/iodide symporter expression and activity involves the PI3K/Akt signaling pathway. Endocrinology 155: 1145-1156, 2014.

24. Palangat M, Grass JA, Langelier MF, Coulombe B and Landick R: The RPB2 flap loop of human RNA polymerase II is dispensable for transcription initiation and elongation. Mol Cell Biol 31: 3312-3325, 2011.

25. Tang SC and Chen YC: Novel therapeutic targets for pancreatic cancer. World J Gastroenterol 20: 10825-10844, 2014

26. Yamaguchi M, Vikulina T and Weitzmann MN: Gentian violet inhibits MDA-MB-231 human breast cancer cells proliferation, and reverses the stimulation of osteoclastogenesis and suppression of osteoblast activity induced by cancer cells. Oncol Rep 34: 2156-2162, 2015. 